\title{
DEVELOPMENT OF THE INDIVIDUAL AND TEAM WORK ATTRIBUTE AMONG UNDERGRADUATE ENGINEERING STUDENTS: TRENDS ACROSS 4 YEARS OF ASSESSMENT
}

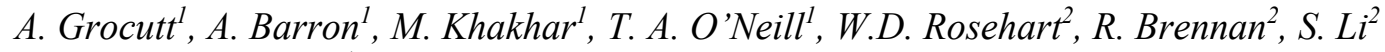 \\ ${ }^{1}$ Department pf Psychology, University of Calgary \\ ${ }^{2}$ Schulich School of Engineering, University of Calgary \\ alyssa.grocutt@ucalgary.ca
}

\begin{abstract}
The Engineers Canada Accreditation Board outlines 12 Canadian Engineering Graduate Attributes required for program accreditation. One of these attributes is Individual and Team Work. Since 2016, at the University of Calgary, there has been a voluntary, undergraduatewide survey administered to the Schulich School of Engineering students every spring via an online platform. The purpose of the survey is to assess students' perceived development of teamwork skills during their program, and identify avenues to improve program offerings. After four consecutive years of this survey, with sample sizes ranging from 683-973 students, there are three main trends that can be identified: students perceive teamwork skills as highly important for their future careers, there are noticeable differences between male and female students regarding teamwork experiences, and students value teamwork skills training and opportunities for peer feedback. Implications of these findings are that there are gendered teamwork experiences among undergraduate engineering students and more research is needed to understand interventions that can mitigate this.
\end{abstract}

Keywords: teamwork, accreditation, professional skills, assessment, graduate attributes.

\section{INTRODUCTION}

The Engineers Canada Accreditation Board outlines 12 Canadian Engineering Graduate Attributes required for program accreditation. One of these attributes is Individual and Team Work. The skill set of Individual and Team Work is defined by the Engineers Canada Accreditation Board as "an ability to work effectively as a member and a leader in teams, preferably in a multi-disciplinary setting" [1]. It has been suggested that teamwork, being a professional skill, can be difficult to formally develop and measure [2]. Furthermore, there is concern within post-secondary education that students may not be sufficiently developing the "professional skills" needed to be successful in their careers $[3,4]$. Since the current world is highly teamfocused [5] it is essential that postsecondary engineering students are graduating with the necessary teamwork skills to excel in their careers. Through the assessment of the Individual and Team Work attribute, engineering programs can ensure they are producing highly competitive graduate students by identifying gaps in students' skills and implementing changes to minimize or eliminate these gaps. To do so, evidence-based measures can be used to assess students' acquisition of teamwork skills. One way to do this is to evaluate students' perceptions of their teamwork skill acquisition during their engineering degree [6], ideally this is done after implementing teamwork skills training [see 7]. For example, at the University of Calgary, the Schulich School of Engineering (SSE) has collaborated with the Individual and Team Performance (ITP) Lab in the Department of Psychology to implement teamwork training workshops to a number of courses as well as to assess the development of the Individual and Team Work attribute among undergraduate engineering students.

\section{METHODS}

Since 2016, the SSE has consulted with the ITP Lab to administer a voluntary, undergraduate-wide survey to the SSE students every spring via an online platform. See Figure 1 for the program year distribution of the 2019 survey. The purpose of the survey is to assess students' perceived development of teamwork skills during their program, and identify avenues to improve program offerings. Results from the survey are subsequently analyzed to identify levels of teamwork competencies among the undergraduate students. The survey contains 56 Likert-type items, three open-ended questions, and two ranking questions. These questions assess students' satisfaction with teamwork, their attitudes towards teamwork, perceptions of the emphasis placed on and support received for teamwork from SSE, teamwork skills (i.e., importance and self-efficacy), conflict experiences 
and challenges, and support for teamwork initiatives. The following are the sample sizes for each survey year $\left(\mathrm{n}_{1}\right.$ represents 2016): $\mathrm{n}_{1}=731, \mathrm{n}_{2}=683, \mathrm{n}_{3}=973, \mathrm{n}_{4}=942$.

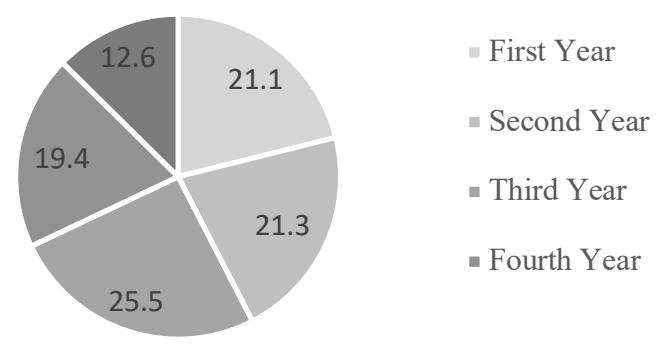

Figure 1: 2019 Program year percentage distribution.

\section{TRENDS}

Each year with the SSE survey there are key trends emerging from data analyses. Comparing across the four survey years there are three key recurring trends that can be identified: students perceive teamwork skills as highly important for their future careers, there are noticeable differences between male and female students regarding teamwork experiences, and students value teamwork skills training and opportunities for peer feedback. The following sections explore these three key trends in detail.

\subsection{Teamwork Skills}

The first key trend is that students perceive teamwork skills as highly important for their careers. However, there are certain skills students feel more competent in than others. Accordingly, it is important to assess which skills students feel they need to improve, and use this information to structure teamwork skills training to develop these skills. The survey conducted by the ITP Lab asks students to rate the extent to which they perceive six skills, representing effective leadership and interpersonal skills, to be important for their future careers. See Table 1 for the six skills assessed. Students are asked to rate the extent to which they feel able to successfully perform each skill (i.e., their self-efficacy in each skill) and the extent to which they perceive each skill to be relevant to their future success in their careers. These ratings are on a 5-point Likert scale ranging from $1=$ to no extent to $5=$ to a great extent.

Table 1: Teamwork skills.

\begin{tabular}{|l|l|}
\hline Skill One & $\begin{array}{l}\text { Confront a team member who doesn't } \\
\text { respond to group emails and } \\
\text { conversations in a timely manner. }\end{array}$ \\
\hline Skill Two & $\begin{array}{l}\text { Address a team member who is not } \\
\text { contributing their fair share to the work. }\end{array}$ \\
\hline Skill Three & $\begin{array}{l}\text { Confront a team member whose quality of } \\
\text { work is not meeting the team's standards. }\end{array}$ \\
\hline
\end{tabular}

\begin{tabular}{|l|l|}
\hline Skill Four & $\begin{array}{l}\text { Address an interpersonal conflict you } \\
\text { have with a team member. }\end{array}$ \\
\hline Skill Five & $\begin{array}{l}\text { Step in and help resolve conflict between } \\
\text { members of your team. }\end{array}$ \\
\hline Skill Six & $\begin{array}{l}\text { Help a team member raise their skill level } \\
\text { to meet the needs of the team. }\end{array}$ \\
\hline
\end{tabular}

The results of the surveys in the SSE show that the skill with the highest average rating of self-efficacy is Skill Five and the skill with the lowest average rating of self-efficacy is Skill Three (see Figure 2 for 2019 survey results). High self-efficacy in Skill Five, the ability to step in when there is conflict occurring between other team members and help resolve that conflict, indicates that students feel they are able to assist their peers with resolving conflict that they are not directly involved in. Low self-efficacy in Skill Three, the ability to confront a team member about the quality of the work they are doing when it is not meeting the quality standards that the team as a whole has, indicates that students may feel as though there is room for improvement in their ability to confront team members about issues regarding work quality specifically. Based on these results it appears that in general a strength students perceive in their teamwork competencies is to help team members resolve conflict and an area of improvement that students perceive is in their ability to confront team members about low-quality work.

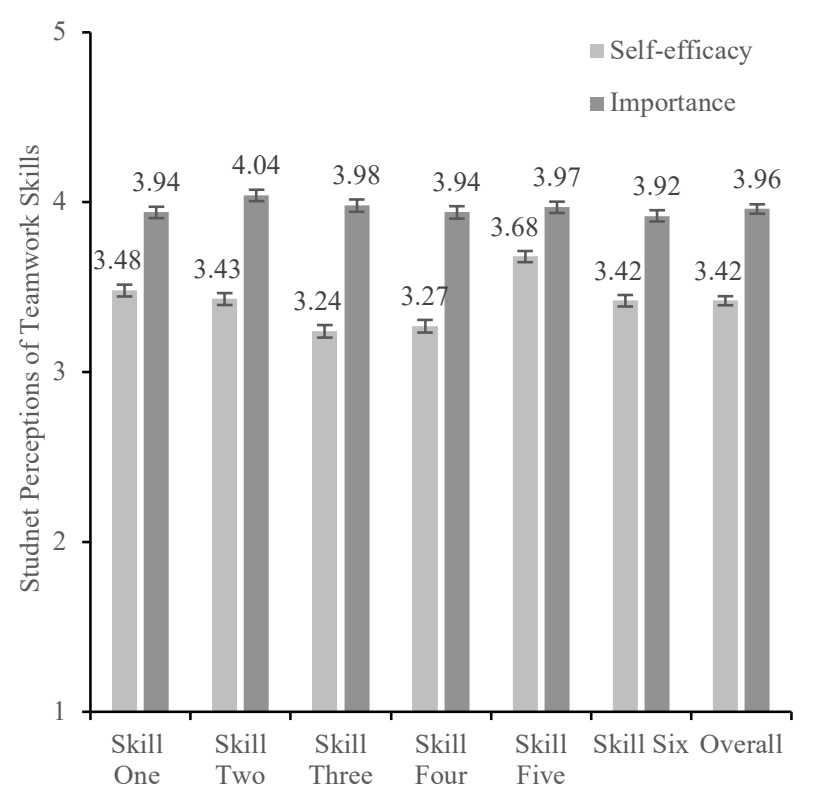

Figure 2: Perceived teamwork skill self-efficacy and importance by skill. Error bars indicate standard error.

\subsection{Gender Differences}

The second key trend identified is that there are noticeable gender differences that warrant attention and further investigation. Specifically, there are noticeable differences between male and female students regarding 
teamwork experiences. There are a number of key significant differences that were identified in the results of the quantitative data. First, female students reported significantly lower ratings of self-efficacy in each of the six teamwork skills included in the survey (see Table 1 for Skills; see Figure 3 for gender differences in perceived self-efficacy from 2019 survey results).

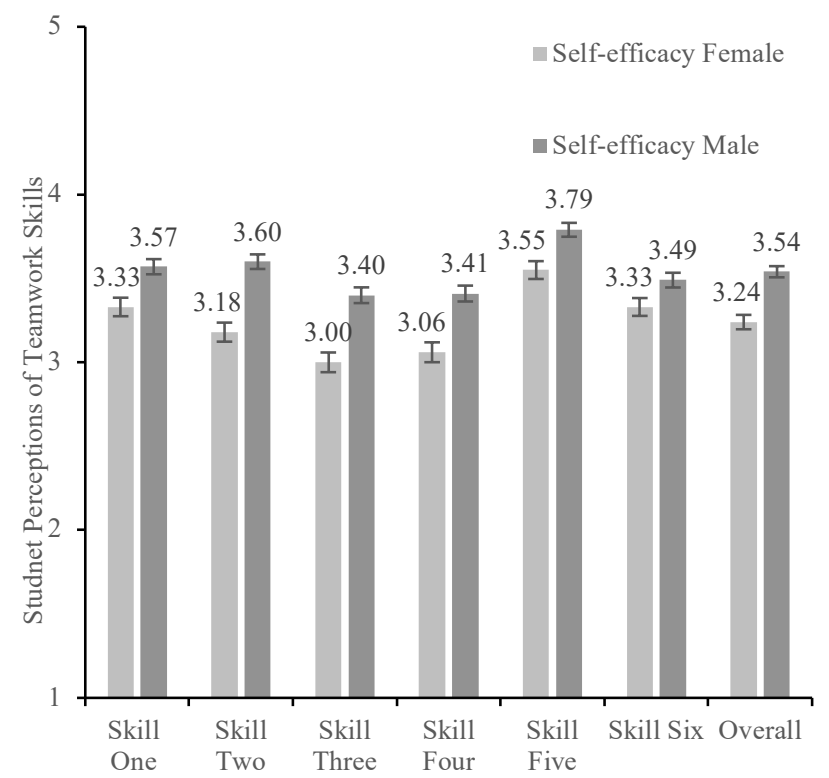

Figure 3: Perceived teamwork skill self-efficacy by gender. Error bars indicate standard error.

Second, female students reported significantly lower ratings of their ability to communicate interpersonal team conflict not only to their peers but also to the SSE departmental faculty members (see Figure 4 for 2019 survey results). These questions asked students to rate the extent to which they believe they are able to effectively communicate conflict to their team members as well as SSE faculty or staff on a 5-point Likert scale ranging from $1=$ to no extent to $5=$ to a great extent. Based on the results, female students feel slightly less than moderately able to effectively communicate conflict to their team members and slightly more than moderately able to communicate conflict with SSE faculty or staff.

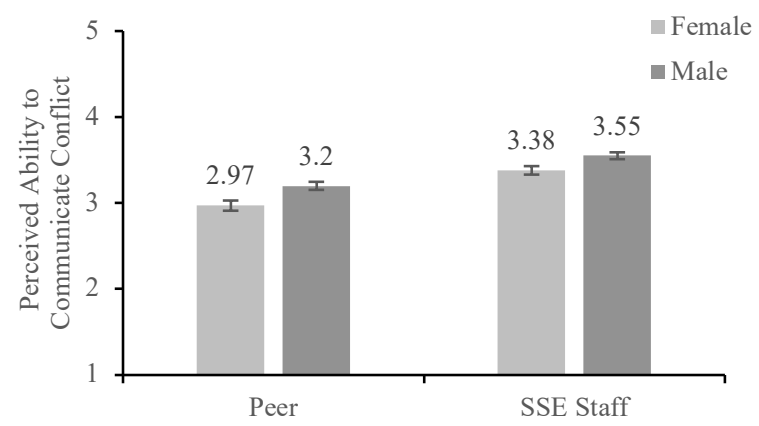

Figure 4: Perceived ability to communicate conflict by gender. Error bars indicate standard error.
Finally, females reported a significantly greater impact of conflict on their personal well-being (see Figure 5 for 2019 survey results). Students were asked to indicate the extent to which they believe that conflict within their teamwork experiences has impacted their personal wellbeing on a 5-point Likert scale ranging from $1=$ to no extent to $5=$ to a great extent. Based on the results, female students feel that conflict within their teamwork experiences has had close to a moderate impact on their personal well-being while males feel conflict within their teamwork experiences has had slightly more than a small impact on their personal well-being.

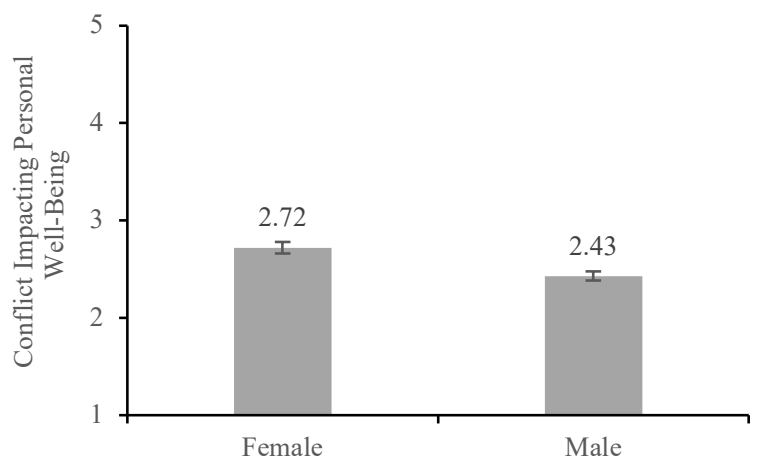

Figure 5: Perceived consequences of conflict by gender. Error bars indicate standard error.

Taken together, these findings suggest an increased need for support targeting female students as it appears by these results that any current additional support for female students is not sufficient. It is important to note that this survey assesses gender groupings largely as a binary (although other options were provided that were not used by respondents) which limits our ability to understand other minority groups that may also benefit from additional support.

To further investigate the trend in gender discrepancies, we examined the open-ended item responses and found reports from female students indicating that they feel they are treated unfairly. From the complaints found in the survey there are two main areas of concern. First, that female students feel they are treated unfairly by their male teammates, and second, that female students do not always feel that their complaints to the faculty members are taken seriously.

\subsection{Teamwork Initiatives}

Finally, the third key trend identified is that students value teamwork initiatives. Students were asked to indicate their support for teamwork initiatives on a 5-point Likert scale ranging from $1=$ to no extent to $5=$ to a great extent. The survey completed by the SSE students contains the following five teamwork initiatives: 
1. More team-based projects.

2. More opportunities for individual grades in team projects.

3. More opportunities for team skills training.

4. More opportunities to give and receive peer feedback.

5. More time in class dedicated to teaching and learning teamwork skills.

Specifically, the two most consistently valued initiatives are teamwork skills training and opportunities for peer feedback (see Figure 6 for 2019 survey results). The continued high support found for these teamwork initiatives indicates that implementing these initiatives could lead to students having more rewarding teamwork experiences and gaining the necessary teamwork skills for their future careers. Students do recognize the importance of team projects for their learning and many students are interested in further increasing the teamwork activities to assist them in the learning of valuable teamwork skills.

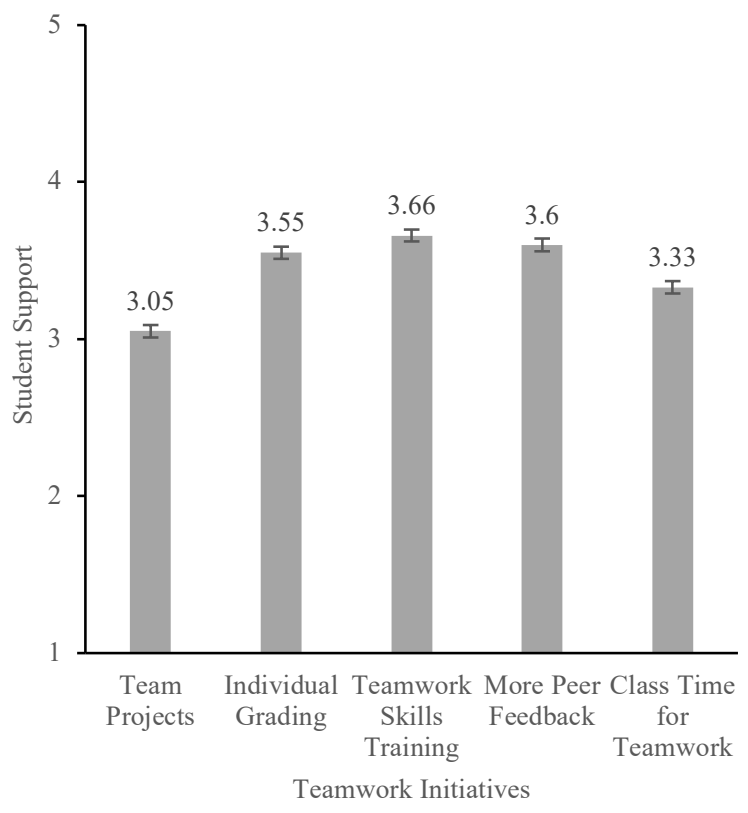

Figure 6: Average student support for teamwork initiatives. Error bars indicate standard error.

\section{DISCUSSION}

Overall, the findings of the annual survey of teamwork skills and experiences among undergraduate engineering students in the SSE show that students are perceiving their competence, or ability, in teamwork skills as generally good. The students are also perceiving teamwork skills as important to develop and are indicating that they support and desire training on teamwork skills.
There are skills that students perceive their ability is less well developed. Additionally, there are important demographic, specifically gender, differences in teamwork skill self-efficacy and in teamwork experiences. Students develop these teamwork skills not only through team projects in their courses, but through teamwork skill training. Specifically, workshops aimed at developing teamwork skills in students. Such workshops involve assessment and feedback often using online platforms (e.g., ITPmetrics.com) that allow for students to gain selfawareness, assess their peers, and receive feedback from their peers. Teamwork interventions such as these workshops have been shown to improve student learning and team performance [see 8-10]; and can help explain the students' perceptions of their own teamwork skills. Specifically, training on constructive controversy [8], peer feedback [10], and feedback on team dynamics [9] have been shown to enhance student teamwork skills as well as student team performance.

At the University of Calgary, the ITP Lab delivers teamwork workshops to various undergraduate engineering courses in the SSE. These workshops include conflict management, team dynamics, team contracts, and constructive controversy. For example, students participate in a workshop that discusses conflict and ways in which to manage team conflict. Based on the results of this annual survey, on average, students have high self-efficacy for their ability to manage conflict between other members of their team. The workshop on conflict management could be one of the reasons that students perceive their ability as high in this skill. However, the results also show that, on average, students perceive lower ability in addressing specific team members about work quality. This indicates that the training may need to address this form of conflict more specifically. These workshops do not address gender, which based on the gender differences in the results, should be reconsidered. Finally, the results show that students do value these workshops and are open to more teamwork skills training.

\section{RECOMMENDATIONS}

Based on the above trends, there are three corresponding recommendations. Implementing the following recommendations can help to fill the gaps identified by the survey results.

\subsection{Teamwork Skills}

Overall, the consistency across years in the results regarding the students' self-efficacy in teamwork skills indicates that students may feel as though there is room for improvement in their ability to confront team members about issues regarding work quality specifically. This deserves some attention on how to improve student's ability since it is an important skill for engineering students to develop in their undergraduate degrees. Additionally, 
the results also indicated that students do perceive this skill as being highly important for their future careers. Based on this information, communication skills training can be structured to ensure that students are provided the information and tools necessary to develop this skill. Communication training has been shown to improve the effectiveness of student teams [8].

One way to do this is to implement teamwork workshops in undergraduate engineering courses [see 8]. Wide application of these workshops across classes involving teamwork can help to improve students' competency in teamwork skills. The repeated exposure to the topics of the workshops can assist in students retaining the information. Moreover, the workshops can be tailored in a way to better address confrontation around work quality. Confrontation is something students often find difficult in the teams which is one reason for the use of peer feedback. However, peer feedback does not always occur at the most optimal time for addressing poor quality work. Therefore, students need to be better equipped with these skills while considering the timing of certain course demands. For example, administering peer feedback before the first major team assignment is due for grading will allow team members to adjust their behaviour accordingly to optimize team performance. Along with peer feedback forms being provided to students, the feedback needs to be debriefed so that students are able to use the feedback they receive in a constructive way [see 9-11]. Ultimately, creating a climate of openness and receptiveness to feedback using many specific approaches seems like the best way forward.

Additionally, facilitated class discussions can be incorporated where the students are asked to brainstorm ideas about ways in which confrontation with team members can be done constructively [8, 12]. This discussion can be followed by a breakout activity in which students discuss confrontation within their own teams. It would be beneficial to have students act out a role play activity involving confrontation regarding quality of work within their teams. This role play activity would need sufficient time provided to ensure that each student has an opportunity to participate. Additionally, following the role play activity there would be a debrief discussing the reason for the activity along with a group discussion on what the students found worked best or what they preferred and what did not work. Not only would this added workshop component provide students with information on how to handle confrontation but, it would also get a discussion going around confrontation which can help make students more comfortable with the topic itself. This method also allows students to learn how other members of their team prefer to have a problem communicated to them. The role play activity is aimed at teaching students practical conflict management skills and along with the repeated exposure to the topics of the workshop can assist students in the retention of this important information. Finally, having students develop team contracts and include the proper way to address team members about poor quality work can further assist students in getting comfortable with the idea of confrontation and assist them in the development of this skill.

\subsection{Gender Differences}

The consistent results, both quantitative and qualitative, of gender differences in teamwork experiences warrants further attention. While women commonly report lower perceived competence than men, the trend that females are reporting lower self-efficacy should be investigated further. Future research should investigate whether these differences in self-efficacy are also differences in actual competence in these teamwork skills. However, regardless of whether these observed differences are only in perceived competence or in both perceived and actual competence, interventions should aim to increase self-efficacy regarding teamwork skills among female engineering students.

Additionally, based on the gender differences found, it is critical that discussions around gender issues and appropriate behaviour are supported and encouraged. These discussions can help increase awareness and create a safe space for all gender identities. A possible first step is to get context-specific information on the perceptions of gendered teamwork experiences from students and teaching staff then subsequently structure workshops for teaching staff on how to promote gender inclusive student teams [see 13].

All students should feel safe not only physically, but psychologically in their teams and educational environment as a whole. When individuals feel psychologically safe in their environment, they are more comfortable and willing to voice their ideas without fear of being embarrassed [14]. Furthermore, teams that perceive a psychologically safe climate engage in more task conflict that subsequently leads to better team performance [15], therefore it is ideal for students to feel psychologically safe in their environment so that they can contribute to their teams, learn the necessary teamwork skills, and have the best teamwork experience possible. As such, psychological safety within teams and engineering programs should be investigated further to better understand these issues faced by female students (and other minority gender identities) as this could be a possible factor involved in the unfavourable teamwork experiences among female students. Additionally, this could help inform what can be done to rectify these issues. Adding a measure of psychological safety to the assessment of the Individual and Team Work graduate attribute will allow for us to determine if team training workshops need to be altered to help facilitate the development of psychologically safe spaces within student teams that can further contribute to better overall teamwork experiences for students. 


\subsection{Teamwork Initiatives}

According to the results, students perceive the teamwork initiatives assessed (more team-based projects, more opportunities for individual grades in team projects, more opportunities for team skills training, more opportunities to give and receive peer feedback, more time in class dedicated to teaching and learning teamwork skills) as important for their teamwork skill development and teamwork experiences. Not only do students perceive these initiatives as important, but research has shown that mere exposure to team projects in courses does not lead to effective learning of teamwork skills for students by itself [9] and individual feedback and evidence-based instruction on teamwork is essential for student's learning of these skills [10]. As such, it is important to implement teamwork initiatives and our results suggest that students would actually like more of these initiatives. The SSE students have consistently indicated a desire for more teamwork skills training as well as more peer feedback opportunities. These two initiatives can be implemented together and can complement one another.

In terms of teamwork skills training, this can include conflict management, team dynamics, team contracts, team leadership, team design, team composition, team project management, and constructive controversy. Implementing these workshops widely across courses would fill students' desires for more teamwork initiatives, as indicated by their high support for more teamwork initiatives, and would help enhance students' self-efficacy in teamwork skills. The students would benefit from this when they are involved in teamwork as they progress in their program and once they enter their career.

\section{CONCLUSION}

In summary, it is essential for students graduating with an undergraduate degree in engineering to have developed teamwork skills as teamwork is not only necessary during post-secondary education, but also in industry careers. The necessity of teamwork skills is reflected in the requirements for accreditation outlined by the Engineers Canada Accreditation Board with the inclusion of the Individual and Team Work attribute. Assessing the development of the Individual and Team Work graduate attribute provides valuable insights into the strengths and areas for improvement in the undergraduate engineering curriculum. The annual assessment of teamwork skill acquisition allows programs to evaluate their level of ongoing achievement in developing these essential skills among undergraduate students. The results of annual assessments provide an indication of what a program is doing that is working well and what can be improved. The results truly capture the student experience which is the best way to evaluate how the students are doing in developing their teamwork skills.

\section{Acknowledgements}

This research was supported by research grants from the Social Sciences and Humanities Research Council of Canada (to the fourth author). It was also supported by graduate scholarships to the second and third authors (Social Sciences and Humanities Research Council of Canada), and a Chair in Engineering Design Systems funded by the Natural Sciences and Engineering Research Council of Canada awarded to the last two authors.

\section{References}

[1] Canadian Engineering Accreditation Board. (2019) 2019 accreditation criteria and procedures. Retrieved from

https://engineerscanada.ca/sites/default/files/accreditat ion/Accreditation-Criteria-Procedures-2019.pdf

[2] Keith Willey and Mark Freeman, "Completing the learning cycle: The role of formative feedback when using self and peer assessment to improve teamwork and engagement." In Proceedings of the 17th Annual Conference of the Australasian Association for Engineering Education: Creativity, Challenge, Change; Partnerships in Engineering Education pp. 751, 2006

[3] Jane Andrews and Helen Higson, "Graduate employability, 'soft skills' versus 'hard' business knowledge: A European study," Higher education in Europe, vol. 33, no. 4, pp. 411-422, 2008.

[4] Marcel M. Robles, "Executive perceptions of the top 10 soft skills needed in today's workplace," Business Communication Quarterly, vol. 75, no. 4, pp. 453-465, 2012.

[5] Steve W. J. Kozlowski and Bradford S. Bell, "Work groups and teams in organizations," Handbook of Psychology, 2003

[6] Keith Willey and Anne Gardner, "Using Self Assessment to Integrate Graduate Attribute Development with Discipline Content Delivery," In Proceedings of 36th European Society for Engineering Education, SEFI Conference on Quality Assessment, Employability and Innovation., (2008, January).

[7] Rania Al-Hammoud, Ada Hurst, Andrea Prier, Mehrnaz Mostafapour, Chris Rennick, Carol Hulls, Erin Jobidon, Eugene Li, Jason Grove, and Sanjeev Bedi, "Teamwork for Engineering Students: Improving Skills Through Experiential Teaching Modules," In Proceedings of the Canadian Engineering Education Association (CEEA)., (2017, June).

[8] Thomas A. O’Neill, Genevieve C. Hoffart, Matthew M. McLarnon, Hayden J. Woodley, Marjan Eggermont, William Rosehart, and Robert Brennan, "Constructive controversy and reflexivity training promotes effective conflict profiles and team functioning in student 
learning teams," Academy of Management Learning \& Education, vol. 16, no. 2, pp. 257-276, 2017.

[9] Magda B. Donia, Thomas A. O'Neill, and Stéphane Brutus, "The longitudinal effects of peer feedback in the development and transfer of student teamwork skills," Learning and Individual Differences, vol. 61, pp. 87-98, 2018.

[10] Thomas A. O’Neill, Amanda Deacon, Katherine Gibbard, Nicole Larson, Genevieve Hoffart, Julia Smith, and Magda Donia, "Team dynamics feedback for post-secondary student learning teams," Assessment and Evaluation in Higher Education, vol. 43, pp. 571-585, 2017.

[11] Thomas O’Neill, Nicole Larson, Julia Smith, Magda Donia, Connie Deng, William Rosehart, and Robert Brennan, "Introducing a scalable peer feedback system for learning teams," Assessment \& Evaluation in Higher Education, vol. 44, no. 6, pp. 848-862, 2019.

[12] Thomas O'Neill and Nicoleta Maynard, "How to Make Peer Feedback in Teams Useful: An Empirical Study,"
In Proceedings of the Canadian Engineering Education Association (CEEA)., (2018, June).

[13] Melissa Marinelli, Sally Male, Lee Von Kim, and Zöe Sydney, "Development of Educators' Resources for Creating Inclusive Teamwork in Engineering and Computer Science," In 30th Australasian Association for Engineering Education Conference., (2019, December).

[14] Amy Edmondson, "Psychological safety and learning behavior in work teams," Administrative Science Quarterly, vol. 44, no. 2, pp. 350-383, 1999.

[15] Bret H. Bradley, Bennett E. Postlethwaite, Anthony C. Klotz, Maria R. Hamdani, and Kenneth G. Brown, "Reaping the benefits of task conflict in teams: The critical role of team psychological safety climate," Journal of Applied Psychology, vol. 97, no. 1, pp. 151-158, 2012. 